\title{
Lugar e não-lugar: espaços da complexidade
}

\author{
Place and non-place: spaces of complextiy
}

\section{Luiz Carlos Schneider}

Universidade de Santa Cruz do Sul - UNISC - Santa Cruz do Sul - Rio Grande do Sul - Brasil

Resumo: Este artigo tem como objetivo refletir sobre a importância dos conceitos de lugar e não-lugar em um contexto de globalização e de profunda transformação dos espaços da sociedade contemporânea. Iniciando pela abordagem geográfica atual dos conceitos, ampliou-se a análise das categorias lugar e não-lugar por meio das contribuições sócio-antropológicas de Marc Augé e Michel de Certeau estabelecendose paralelos sobre a sua complexidade de sentidos e significados em diferentes áreas do conhecimento.

Palavras-chave: Lugar. Não-lugar. Cotidiano.

Abstract: This article aims to reflect on the conceptual meanings of place and nonplace in a context of globalization and deep transformation of contemporary society's spaces. Starting from the current approach of geographical concepts, the analysis of the categories of place and non-place was widened through social-anthropological contributions of Marc Augé and Michel de Certeau settling on parallels about the complexity of senses and meanings in different areas of knowledge.

Keywords: Place. Non-place. Practices. 


\section{Introdução}

Em paralelo ao processo de globalização e de propagação instantânea das informações em escala planetária, da rapidez dos fluxos econômicos e do sistema de transportes que encurtam distâncias, a sociedade e as ciências procuram "... aprender a lidar com um avassalador sentido de compressão dos nossos mundos espacial e temporal." (HARVEY, 2003, p.221). Pois o conjunto desses fenômenos têm também profundas implicações relacionadas à percepção individual e coletiva de tempo e espaço. Entre o global e o local, suas diferentes dimensões espaciais e interações econômicas, sociais, culturais, políticas, encontra-se também um espaço fundamental: o lugar da vivência e da existência do homem. Do que denominamos de lugares integrados aos espaços do cotidiano e que convivem em uma relação dialética mundo-lugar-sujeito cuja apreensão em sua totalidade é ainda um desafio para as diferentes áreas das ciências humanas e sociais.

Lugar é um conceito teórico muito utilizado em áreas como a geografia, arquitetura e urbanismo, paisagismo e ecologia, pois a sua fundamentação teórica possui um enfoque físico-territorial que opera sobre um campo de estudos espacial. Contudo, Castello (2007, p. 37) destaca que é importante perceber que o conceito de lugar é transversal (ou um cruzamento multidisciplinar) á uma grande variedade de disciplinas que são voltadas aos estudos dos fatores humanos, sociais, políticos e econômicos. Por este motivo que, conforme o mesmo autor, há uma interpretação variada do conceito de lugar e que pode ser tanto geográfico quanto arquitetônico, antropológico, psicológico ou pertencente ainda a outras áreas do conhecimento, sendo importante lembrar que a individualização do conceito é insuficiente para apreender o seu real significado.

Este artigo tem o objetivo de propor uma reflexão sobre alguns dos principais conceitos de lugar e não-lugar em um contexto de profunda transformação dos espaços da sociedade contemporânea. Pela complexidade e amplitude do tema quer-se esclarecer que as abordagens têm caráter introdutório, ou seja, constituem um recorte sintético de alguns dos principais conceitos e teorias de autores selecionados nas áreas da geografia e da antropologia social e urbana. Desta forma procura-se ampliar as dimensões de complexidade de sentidos e de apropriação disciplinar das categorias.

Para tanto, em um primeiro momento apresenta-se o conceito de lugar por meio de uma abordagem realizada em relação à geografia crítica, onde prevalece um viés marxista e da geografia humanística voltada à percepção dos espaços e seus significados. Destas duas abordagens destacam-se os pontos de vista conceituais e possíveis complementaridades e contradições. Na sequência, e em um segundo momento, expõem-se as contribuições de Marc Augé e de Michel de Certeau. A partir deste viés antropológico e sociológico procura-se explicitar conceito de lugar e de não-lugar destes autores, bem como suas implicações em relação à transformação e apropriação dos espaços físicos e sociais. Por fim apresentam-se também reflexões sobre a complexidade do tema e das abordagens realizadas na forma de considerações sobre os sentidos e significados dos conceitos, suas interações e formas de abordagens sobre os espaços.

\section{A abordagem geográfica de lugar e suas concepções}

Conforme Moreira (2007, p.60), o conceito de lugar na geografia pode ter um duplo entendimento estando relacionado tanto com as teorias de viés marxista e que concentram as discussões de autores como David Harvey, Yves Lacoste, Neil Smith (entre outros) destacando-se a produção de Milton Santos e Ruy Moreira no Brasil, quanto às da geografia de percepção ou humanista (como exemplo Yi-Fu Tuan, Edward Relph, Christofoletti, Paul Claval, Roberto Corrêa).

Em relação à Geografia Crítica prevalecem conceitos como os de Milton Santos, sendo que para este autor lugar é o ponto de uma rede formada pela sobreposição da horizontalidade (contiguidade - 
integração de ligações em uma unidade regional de espaço, vínculo com a produção) com a verticalidade (nodosidade - fluxos com o mundo e circulação de produtos e informações). A cada ponto ou local de interseção das redes horizontais e verticais sobre a superfície do planeta, portanto, origina-se um lugar, o que confere ao todo da globalização um caráter fragmentário originando tanto a inclusão quanto exclusão dos espaços conforme a correlação de forças dos seus componentes sociais e econômicos. Por isso cada lugar é diferente entre si e, segundo Moreira (2007, p.60) “... é o lugar que existe e não o mundo, de vez que são as coisas e os lugares que se mundializam e não o mundo".

Para a geografia crítica, portanto, a especificidade do lugar provém do papel que este representa como singularidade atravessada por fluxos globais e locais e com os quais mantém uma relação dialética. O lugar se define pelas relações que mantém com a totalidade sendo que seu significado também pode sofrer alterações na mesma medida em que o capitalismo se transforma (BARTOLY, 2011, p.68). Na perspectiva do materialismo histórico dialético há uma concepção de mundo ou método que permitiria a compreensão do homem como ser social em conjunto com asrelações políticas e econômicas responsáveis pelas profundas desigualdades espaciais existentes. A concepção da geografia crítica, valorizando mais os aspectos econômicos e políticos, estabelece uma relação entre as escalas do global, nacional, regional e local. Contudo, é preciso lembrar que local é uma noção cartográfica, de posição e localização. E conforme lembra Bartoly (2011, p. 67) o lugar contém o local, mas vai muito além dele, pois é culturalmente definido.

Yi-Fu Tuan, geógrafo chinês, foi um dos autores mais importantes na geografia humanística, e que por meio de sua obra "Espaço e lugar", deixou importantes contribuições para entender estas categorias. Para Tuan, espaço é um termo mais abstrato que lugar, pois se o primeiro começa como espaço indiferenciado transforma-se em lugar na medida em que o conhecemos melhor e o dotamos de valores atribuindo-lhe definições e significados (CASTELLO, 2007, p.60). Portanto, lugar é um espaço humanizado. Tuan, que foi também o criador do termo "topofilia" (ligação afetiva entre a pessoa e o seu espaço de vivência) acentua a importância da transdisciplinaridade no estudo da categoria lugar destacando a ênfase que deve ser dada a percepção ambiental, ao simbolismo da paisagem, a cultura, a estética, entre outros aspectos.

Também na linha humanística, outro nome a ser destacado é o de Edward Relph, geógrafo cujo trabalho trouxe à discussão tanto a "lugaridade" (placeness) quanto a "falta de lugaridade" ou em outra possível tradução "des-lugar"? (placelessness) no estudo dos lugares. Segundo Castello (2007, p. 71), a essência do lugar para Relph seria “...seu poder de estabelecer relações espaciais com as experiências existenciais humanas. O lugar teria, então, uma qualidade essencial, qual seja, sua força de interagir com o modo espacial que tomam as intenções, experiências e comportamentos dos humanos. Em oposição a lugaridade, que é o "sentido" em si do lugar, Relph trouxe de forma inovadora o termo "des-lugar" com o objetivo de mostrar que determinadas padronizações espaciais uniformes e homogeneizadas corresponderiam à perda ou falta de significados dos lugares. Para Relph a inclusão do estudo do cotidiano é uma necessidade para compreender as reais relações entre lugar e as práticas, hábitos e os modos de vida do homem.

Em síntese, portanto, a geografia humanística, embasada na fenomenologia, tem sua abordagem voltada à valorização da experiência do indivíduo ou do grupo social procurando-se entender tanto os comportamentos como as formas de percepção dos sujeitos em relação ao seu lugar de vivência. Conforme Costa e Rocha (2010), as noções de espaço e lugar tem ali seu surgimento como conceitos-chaves sendo que "... o lugar é aquele em que o indivíduo se encontra ambientado, no qual está integrado. O lugar não é toda e qualquer localidade, mas aquela que temsignificância afetiva para uma pessoa ou grupo de pessoas." (COSTA E ROCHA, 
2010, p.37). Por isso o lugar é o espaço vivido, carregado de afetividade e significados.

Nisto concorda Moreira (2007, p.61), para quem na geografia fenomenológica o lugar deriva de uma percepção ou sentido de pertencimento onde coexiste a identidade biográfica do homem com todos os elementos do seu espaço vivido. Conforme este autor há um profundo sentimento de ambiência e de identificação recíproca no lugar em uma singular ligação histórica entre coisas, objetos e a própria vida e o cotidiano dos habitantes. Desta forma, o lugar é estudado a partir das relações e ligações subjetivas estabelecidas entre o sujeito e o espaço que ocupa. E são, portanto, acrescentados nos estudos ás percepções individuais, os significados, as características e heranças culturais, símbolos, os valores $e$ as identidades coletivas (COSTA E ROCHA, 2010, p.51).

As abordagens mais recentes têm procurado conciliar as visões entre a geografia crítica e humana. Pois é exatamente a tensão dinâmica da objetividade e da subjetividade que origina o lugar, em uma dimensão material, com uma localização objetiva no espaço, e outra dimensão abstrata relacionada aos símbolos e significados atribuídos pelos indivíduos e grupos sociais (BARTOLY, 2011, p.69). Mesmo que, em um primeiro momento, a geografia crítica privilegiasse seu enfoque sobre o espaço geográfico em si (valendo-se mais de conceitos como território), geógrafos como Milton Santos passaram também a abordar e a conferir maior importância ao conceito de lugar. Ainda assim a abordagem crítica procura se distanciar da humanista, pois enfoca as influências dos processos econômicos, políticos e sociais que estão relacionados à globalização.

Mas conforme Santos (2002, p.313), a globalização faz também redescobrir novas relações com o mundo que deixa de ser local-local para tornarse um fenômeno de interação global com o local. Neste sentido os lugares, e que refletem a dimensão espacial do cotidiano, podem ser vistos como um meio intermediário entre o mundo e o indivíduo. Para o autor este contexto atual de globalização, localização e fragmentação estão em uma relação dialética entre as necessidades do regime de acumulação do capital, a dissociação de processos e atividades bem como a individualização dos elementos no espaço. Portanto "cada lugar é, à sua maneira, o mundo" (SANTOS 2002, p.314). Ou seja, em virtude das redes de transporte e comunicações, cada lugar passa a ser virtualmente mundial. Por outro lado essa nova realidade corresponde também a uma ampliação da sua individualidade e diferença em relação aos outros lugares. Neste fenômeno, contudo, o autor também alerta para os riscos de uma simplificação cega sobre o assunto e que desconsidere outros elementos além das forças sociais globais. Por estes motivos, e para Santos (2002, p.314), há uma redescoberta da dimensão local e da necessidade de repensar o lugar e seus novos significados. Paraeste autor “... uma dada situação não pode ser plenamente apreendida se, a pretexto de contemplarmos sua objetividade, deixamos de considerar as relações intersubjetivas que a caracterizam." (SANTOS, 2002, p.315).

Portanto, pode-se perceber que para Santos 0 cotidiano está enriquecido pelos papeis que a informação e a comunicação assumiram em todos os aspectos da vida social. Sua preocupação é entender o conteúdo geográfico do cotidiano por meio da sua materialidade, mas também por meio da complexa relação entre espaço e movimentos sociais. "A localidade se opõe a globalidade, mas também se confunde com ela." (SANTOS, 2002, p.321). É no lugar e no cotidiano compartilhado entre pessoas, negócios e instituições que forma-se a base para a vida comum. "O lugar é o quadro de uma referência pragmática ao mundo, do qual the vêm solicitações e ordens precisas de ações condicionadas, mas é também o teatro insubstituível das paixões humanas, responsáveis, através da ação comunicativa, pelas mais diversas manifestações da espontaneidade e da criatividade." (SANTOS, 2002, p.322).

\section{Lugar e não lugar: o olhar de Augé e Certeau}

Para o antropólogo Marc Augé, os espaços antropológicos são todos aqueles que apresentam 
fortes vínculos sociais e culturais constituindo-se em espaços existenciais, de profunda relação do indivíduo com o mundo que o cerca. Em sua obra "Não lugares: Introdução a uma antropologia da supermodernidade", e utilizando como exemplo um poema de Baudelaire referente a uma paisagem urbana do século XIX em que conviviam e se misturavam chaminés e campanários, o autor destaca o que Starobinsky já denominava "marcha de baixo", ou seja, uma evocação subjetiva dos ritmos antigos que perduram e que preservavam todas as temporalidades mesmo com 0 surgimento damodernidade. Essa imagem refere-se metaforicamente a uma relação espaço e sociedade em que as permanências ou as "forças" do lugar (culturais, sociais, simbólicas) estavam reconhecidas e assimiladas convivendo de forma simbiótica com as alterações do presente.

O núcleo do conceito de lugar para Augé é próximo dos conceitos da geografia humanista onde lugar é o espaço vivido, do cotidiano, e que carrega consigo a afetividade e a memória. Lugar, para este autor, é definido como um espaço antropológico e que apresenta características identitárias, relacionais e históricas. Inclui ainda a possibilidade dos percursos que nele se efetuam, dos discursos que nele se pronunciam e da linguagem que o caracteriza. A oposição a estes espaços são os não-lugares, ou então, todos não identítários e com os quais o sujeito não consegue estabelecer vínculos relacionais durante a sua ocupação. Contudo, Augé alerta para o fato de que as categorias de lugar ou de não-lugar não existem em uma forma absoluta, pura. Essas duas categorias devem ser vistas antes como polaridades onde tanto os próprios lugares e as relações se recompõem e onde ".... primeiro nunca é totalmente apagado e o segundo nunca se realiza totalmente" (AUGÉ, 1994, p.74).

O surgimento do que o autor denomina de supermodernidade é responsável pelas principais transformações de sentido na relação espaço e sociedade. A supermodernidade, a qual o autor se refere como marca de nossa época, tem sua origem em três aspectos que são relacionados ao excesso: a superabundância factual, a superabundância espacial e a individualização das referências. Estes fatores podem encontrar sua materialização plena nos nãolugares. Pois para Augé os não-lugares correspondem aos espaços funcionais construídos com determinadas finalidades objetivas (comércio, transporte, lazer) e o tipo de relação e de experiências transitórias, supérfluas, funcionais que os indivíduos e grupos mantém com esses espaços. São realidades complementares e em oposição aos espaços antropológicos, onde se este último é capaz de criar um social orgânico o outro cria uma tensão solitária (AUGÉ, 1994, p. 87).

Os não-lugares, portanto, e ao contrário dos lugares, são esvaziados do princípio de sentido para aqueles que o ocupam ou habitam. Em sua expressão urbana ou arquitetônica apresentam uma arquitetura estandardizada voltada ao modismo e ao consumo, concepções de ambiências funcionais e de caráter transitório e que, sendo plenamente reconhecidos e assimilados pela sociedade moderna, não promovem relações sociais autênticas e genuínas (BARTOLY, 2011, p. 76). Portanto, para este autor os não-lugares promovem e se constituem de uma homogeneização não somente dos espaços urbanos e arquitetônicos mas também das experiências sociais. São resultados de projetos do espaço (estratégias da ordem para Certeau) que desconsideram as forças e asignificância própria dos lugares constituindo-se em ações uniformes e planejadas com objetivos práticos e funcionais. Para o autor, os não-lugares também tenderiam à reprodução de suas características o que poderia criar uma falsa sensação de familiaridade em meio à transitoriedade. Se Augé considera os não-lugares como "medida da época" é porque a profusão destes é quantificável em superfícies, volumes e distâncias produzidas, pois incluem espaços construídos em profusão tais como os meios de transporte (vias e todos os tipos de estações), as grandes cadeias de hotéis, os centros comerciais, os shoping centers, parques entre outros. Corresponderiam, portanto, a um desvirtuamento das emoções legítimas e autênticas da memória e da afetividade, estando em 
oposição ao lugar antropológico capaz de reter e ser espaço criador de identidade, pois se refere ao lugar de origem, concreto e ou simbólico e histórico (AUGÉ, 1994, p.77). A supermodernidade em si, é produtora de não-lugares, que também não integram os lugares antigos ou de memória.

Todos esses tipos de espaços produzidos pelos não-lugares visam ao consumo do homem "médio", que é, como exemplo, um usuário dos sistemas rodoviário, comercial ou bancário. "Enquanto a identidade de uns e de outros é o que constituía o lugar antropológico, por meio das conivências da linguagem, dos sinais da paisagem, das regras não formuladas do bem viver, é o nãolugar que cria a identidade partilhada dos passageiros, da clientela ou dos motoristas domingueiros." (AUGÉ, 1994, p. 93). Por isso o usuário do não-lugar está em uma relação contratual. Uma relação que privilegia o consumo contemporâneo, pois ao mesmo tempo em que há rígidos critérios para verificação da identidade individual (controle para acesso e saída do sistema), há por parte dos usuários uma relativa libertação de si mesmos para usufruir dos espaços de forma quase anônima e com uma sensação libertária. Contudo são espaços que não criam nem relação social nem identidade singular e que podem propiciar certo vazio existencial: "...o espaço da supermodernidade é trabalhado por esta contradição: ele só trata com indivíduos (clientes, passageiros, usuários, ouvintes) mas eles só são identificados, socializados e localizados (nome, profissão, local de nascimento, endereço) na entrada e saída." (AUGÉ, 94 p.101). Não-lugar é o contrário da utopia, são espaços que precisam de controle ao mesmo tempo em que retiram a identidade do indivíduo criando uma sensação de solidão e similitude.

Augé discorre também sobre esse tipo de produção dos não-lugares da supermodernidade (estradas, aeroportos) e sua definição pelas palavras ou textos que nos propõem. Como exemplo podemos utilizar a diferença entre uma estrada e um caminho. O percurso rodoviário deve evitar, por necessidade funcional, parar em pontos notáveis. Contudo estes lugares ou pontos notáveis ao longo da estrada passam a ser profusamente sinalizados com informações históricas destes espaçosou mesmo com anúncios comerciais de produtos ou serviços locais, etc. Com o passar do tempo o viajante passa a ter familiaridade com o espaço abstrato do que leu mas não conheceu de fato estes lugares. Portanto o objetivo da estrada (um não-lugar) é o da realidade funcional, o de ligar dois pontos, é o destino final, a economia de tempo e a racionalidade do uso do espaço. Diferente de um caminho onde os locais se anunciam e onde há a descoberta e a relação vivida entre o sujeito e o espaço. Na estrada não interessa a descoberta e a relação do espaço com o sujeito, observa-se e assimila-se o que pode e o que deve ser lido, percebido, vivido.

A superabundância de informações em todos os espaços também cria uma experiência de presente perpétuo. Os não-lugares são espaços repletos de textos e imagens que difundem as instituições que os sustentam e também, evidentemente, têm o objetivo de reforçar as relações de consumo. Por isso também incentivam o indivíduo a uma atitude narcisista: a agir como todos para ser você mesmo (AUGÉ, 1994, p.97). Frases de caráter normativo, informativo ou mesmo proibitivo criam uma interação impessoal e que remetem à percepção de isolamento do indivíduo. Os não lugares-reais da supermodernidade utilizam-se de códigos, normas, instruções para serem utilizados porque: "...assim são instaladas as condições de circulação em espaços onde se supõe que os indivíduos só interajam com textos, sem outros anunciantes que não pessoas morais ou instituições (aeroportos, companhias aéreas, ministério dos transportes, sociedades comerciais, polícia rodoviária, municípios) cuja presença se adivinha vagamente ou se afirma mais explicitamente." (AUGÉ, 1994, p. 89).

Por todos estes motivos o autor define e aponta os não-lugares como a escolha dos espaços da supermodernidade. Cita como exemplo algumas situações comuns vivenciadas no cotidiano e que se encontram-se em oposição tais como: um trevo (visto como local de fluxos e com lógica funcional) ao 
cruzamento (onde as pessoas se encontram); os conjuntos habitacionais periféricos (e a ausência da vida social ou coletiva destes espaços) aos monumentos (símbolos, signos, memória coletiva) (AUGÉ, 1994, p. 98). Contudo, como adverte “...na realidade do mundo de hoje, os lugares e os espaços, os lugares e os não lugares misturam-se, interpenetram-se." (AUGÉ, 1994, p. 98). O não-lugar é o espaço por excelência da supermodernidade onde ocorrem novos e diferentes tipos de relações sociais e humanas, ou como poderia se supor: o risco das não relações ou da dissolução das mesmas.

$\mathrm{Na}$ busca de relativização do conceito de nãolugar proposto por Augé expõem-se o conceito de espaço e de lugar proposto por Michel de Certeau, filósofo de formação, historiador e cuja obradeixou também uma imensa contribuição para análise sociológica. Certeau (1994) faz uma crítica a cidadeconceito instaurada pelo discurso utópico e urbanístico, racional, funcionalista, que privilegia o progresso e serve como balizadora para as estratégias socioeconômicas e políticas. Ao mesmo tempo enfatiza que: "... se de um lado a linguagem do poder se urbaniza, por outro existem movimentos contraditórios que se compensam e se combinam fora do poder panóptico." (Certeau, 1994, p. 174). Por isso, complementa que "...sob os discursos que a ideologizam, proliferam as astúcias e as combinações de poderes sem identidade, legível, sem tomadas, apreensíveis, sem transparência racional impossíveis de gerir." (CERTEAU, 1994, p. 174). Em outras palavras, Certeau fala da possibilidade de manipulação da ordem espacial estabelecida por meio do indivíduo e que é agente ativo na produção do espaço.

Para o autor, a cidade se degrada em um mesmo ritmo dos procedimentos e da ordem que a estrutura. Contudo, Certeau não permanece neste discurso de caráter pessimista e envereda por outras perspectivas propondo analisar o que chama de "práticas microbianas", que considera singulares, plurais, ilegíveis, impossíveis de serem controladas, sobreviventes e que se constituem das práticas cotidianas e das "criatividades sub-reptícias" do espaço vivido. Em síntese, fala de uma cidade e de um lugar que emerge de uma determinada razão ou racionalidade voltada ao controle e às formas como as pessoas comuns, ou usuários, operam neste lugar em um sentido oposto a racionalidade praticada. Neste sentido, a aparente conformidade dos usuários pode até esconder essas lutas constantes, individuais e cotidianas, subconscientes, contra uma determinada racionalidade. Tais aspectos, para o autor, devem ser aprofundados pelas ciências sociais, motivo pelo qual procura estabelecer uma discussão formal sobre os conceitos chaves das estratégias e táticas. O primeiro relacionado à ordem dominante ou então "de cima", a um lugar de poder relacionado às ações que parte de sistemas e discursos totalizantes. São promovidas, por exemplo, pelas instituições em geral, pelos estabelecimentos comerciais, pela produção sociocultural e são capazes de articular um conjunto de lugares físicos. A estratégia é uma forma de calcular ou de manipular "....relações de força que se tornam possíveis a partir do momento em que um sujeito de vontade ou poder é isolável e tem lugar de poder ou de saber." (CASTELLO, 2007, p. 103). O segundo conceito-chave, tático, relacionado às pessoas comuns e a toda subjetividade ligada ao que chama de "...as mil maneiras de fazer", as formas de transgressão ou práticas de driblar e reinventar o cotidiano. A tática, portanto, desenvolve--se onde não há poder e não obedece a "lei" do lugar. Conforme Souza Filho (2002, p.133):

"A crença na liberdade das práticas anônimas,
"sem nome próprio", mesmo quando
reduzidas ao silêncio, e o olhar sensível aos
movimentos das resistências, mesmo
mínimas - mas, como claros na noite,
surpreendes, perturbadoras -, constituem na
obra Michel de Certeau, instrumentos de
pesquisa capazes de permitir enxergar o que
se passa nos minúsculos espaços sociais em
que as táticas silenciosas e sutis jogam com o
sistema dominante. Instrui-nos Certeau, na
cultura ordinária, cotidiana, "a ordem é jogar",
isto é, por meio da astúcia, driblar o sistema,
fingir seu jogo. O sistema? Este às vezes
"fecha os olhos". Assim, no próprio interior da
ordem instituída, anuncia-se a resistência à
reprodução uniformizante."

Sendo assim e ainda conforme Souza Filho (2002, p. 131), as análises de Michel de Certeau 
sobre a vida cotidiana partem de uma hipótese central: "...é erro supor que o consumo das idéias, valores e produtos pelos anônimos sujeitos do cotidiano é uma prática passiva, uniforme, feita de puro conformismo às imposições do mercado e dos poderes sociais.". Assim podemos entender que para Certeau existe uma correspondência entre o consumo dos bens culturais ou materiais e as suas respectivas imposições sociais com as formas de suas apropriações e ressignificações as quais podem apresentar os mais imprevisíveis tipos de inércia ou mesmo resistência pelos sujeitos ou grupos sociais.

Para Certeau lugar é regra, doutrinação, poder, objetiva a disciplina e faz parte do domínio do estratégico. Lugar indica uma posição de estabilidade, uma configuração de posições e "...é a ordem (seja qual for) segundo a qual se distribuem elementos nas relações de coexistência." (CERTEAU, 94, p. 201). Já o não-lugar constitui-se em uma construção de sentidos ligadas as práticas ou táticas e que são capazes de alterar o sentido da estratégia. Espaço para o autor existe na medida em que se consideram elementos como direção, velocidade e tempo, pois o define como o lugar praticado, vivenciado. Usando a linguística faz uma comparação do espaço com a palavra e do lugar com a enunciação, ou seja, no instante em que a palavra é dita ela é também atualizada. Da mesma forma exemplifica que "...a rua geometricamente definida por um urbanismo é transformada em espaço pelo pedestre." (CERTEAU, 94, p. 201). Para Certeau o próprio ato de caminhar e a motricidade dos pedestres, no que chama de espaço de enunciação, são um exemplo das formas de apropriação e de realização espacial do lugar. Caminhando o sujeito apropria-se das possibilidades permitidas pela configuração espacial do lugar assim como um locutor se apropria da língua. O movimento é a realização espacial do lugar assim como dizer uma palavra é o ato sonoro da língua. "Por fim, implica relações entre os outros indivíduos que ocupam o mesmo espaço, na forma de contratos pragmáticos, mesmo que implícitos." (REIS, 2013, p. 141). "Quando Michel de Certeau fala em não-lugar é para fazer alusão a uma espécie de qualidade negativa do lugar, de uma ausência do lugar em si mesmo que lhe impõe o nome que lhe é dado."(AUGÉ, 1994, p. 93). É o caso, por exemplo, dos itinerários onde o espaço do viajante seria uma espécie de arquétipo do nãolugar já que o mesmo se experimenta como espectador sem se importar realmente com a natureza do espetáculo.

Em síntese, o espaço para Certeau é a prática do lugar ou as formas como os sujeitos o transformam a partir de suas apropriações, ocupações e vivências. Sem a mobilidade, por exemplo, não haveria espaço, mas sim, somente lugares fixos. O espaço supõe um lugar animado por um deslocamento; ele é "um cruzamento de móveis", é portanto um "lugar praticado". Por este motivo Certeau tem um interesse especial pela figura do andarilho e dos sujeitos que em seu cotidiano traçam itinerários como se fosse um discurso construído pelo caminhante. A abordagem de Certeau é focada nos modos do sujeito se inserir no mundo por meio das práticas comunicacionais, da linguagem ou mesmo de suas caminhadas na cidade. Constituem-se em significados e discursos enquanto produtos das interações entre o sujeito e o mundo diferenciando lugares e espaços pela forma de apropriação dos sujeitos.

\section{Um lugar de reflexão sobre os conceitos}

A partir dos conceitos e de algumas das principais ideias dos autores citados neste artigo expõem-se algumas reflexões e considerações finais. Em relação às abordagens realizadas pelas geografias crítica e humanista percebem-se duas dimensões distintas e complementares entre si sobre a definição de lugar. O conceito da categoria lugar, nos dois posicionamentos, possui sentidos diferenciados. O primeiro deles, de viés marxista, voltado à relação nodal e focado nas relações econômicas e políticas e o segundo procurando entender a relação de pertencimento e os espaços de vivência do homem. Em comum destacam a importância do estudo do lugar enquanto espaços 
que, além de sua determinação atual pela forma e conteúdos da rede global possam ser integrados como espaços de vivência do homem. Pelas contribuições de Milton Santo percebe-se também a ênfase do autor (assim como a de outros autores da linha humanística) ao cotidiano. Consideram o cotidiano como sendo de fundamental importância enquanto categoria analítica para entender as "forças" do lugar. Lugares que se moldam e se configuram sob influência das forças globais hegemônicas mas também se adequam, se adaptam e se diferenciam de forma singular. Pois se de um lado a ideia de lugar remete à inclusão ou exclusão dos espaços em termos globais, por outro, também significa os modos de apropriação e vivência dos grupos sociais, suas particularidadeshistóricas, culturais e simbólicas. Aqui, conforme o mesmo autor, apresenta-se o desafio das ciências humanas e sociais em termos metodológicos para uma apreensão mais completa dos diferentes sentidos de lugar, em especial e por meio do estudo do cotidiano.

Os conceitos de Augé são importantes contribuições para entender os lugares e especialmente, a lógica de produção dos não-lugares na sociedade contemporânea. É o olhar do antropólogo. Augé utiliza como base o conceito do lugar antropológico, e que tem em sua essência muita similaridade com o conceito de lugar da geografia humanística. E é por meio da visualização de uma supermodernidade que o autor percebe profundas transformações na construção e (re)significação dos espaços. Suas observações sobre o que denomina de supermodernidade e que em parte correspondem a fenômenos também interligados a globalização, buscam compreender o sentido das novas interações entre espaços e sociedade. Ao utilizar os valores identitários, relacionais, históricos que podem ou não estar presente no cotidiano das pessoas estabelece referências para entender e distinguir os espaços de caráter orgânico, genuínos e autênticos (lugares) dos que considera artificiais em termos de relações humanas (não-lugares). Diferencia-os pelos sentidos e significados da sua produção bem como pelas formas de sua apropriação. A presença destes espaços, diz o autor, também não se apresenta em forma pura, absoluta, mas em diferentes graduações, interpenetram-se. Mas por outro lado, talvez fosse necessário também refletir sobre a existência de espaços que possam ser inclusive indiferenciados ao cotidiano, ou aqueles que, conforme Bartoly (2011, p. 80) argumenta “...não pertencem ao nosso cotidiano, havendo portanto um relativo ou total desconhecimento de seus sentidos e de sua identidade". Trata-se de uma possibilidade.

Mas Augé instiga a novas perguntas. Seria o fenômeno (quantificável conforme o autor) de profusão dos não-lugares da supermodernidade correspondentes também a certas formas de exclusão social e de acesso a estes espaços? Alias, seria essa exclusão somente social? Ou incluiria também uma seleção de comportamentos e práticas? Por exemplo, para Bordieu (1998, p. 164), o capital permite selecionar, conforme suas conveniências e necessidades, quais são os diferentes grupos sociais e coisas desejáveis em um determinado espaço. Desta forma otimiza também custos relacionados a distâncias e tempo. "A falta de capital prende a um lugar." (BORDIEU, 1998, p. 164). Em outros termos, o sucesso nas disputas e nas oportunidades de apropriação dos diferentes bens serviços materiais e culturais dependem dos tipos de capital acumulado (econômico, social, cultural, simbólico).

A exposição de Augé sobre a abundância da construção de "não-lugares" é um alerta para a produção de lugares artificiais enquanto formas plenamente integradas à sociedade em meio a uma intensidade cada vez maior de fluxos de pessoas, mercadorias e informações de todo tipo. Este seria também o motivo de certo incômodo ou angústia existencial da sociedade contemporânea em busca de um sentimento familiar, de comunidade, enraizamento e sentido histórico, identidade. Um contraponto as questões levantadas por Augé, e referentes à pasteurização ou homogeneização dos espaços, construídos pelos ideais da produção e do consumo e sujeitos a uma transitoriedade de utilização é o de que, em que pesem as críticas à autenticidade dos sentimentos considerados artificiais 
e sua relação com o espaço deve-se também considerar que o próprio lugar também age de forma particularizada sobre o global. Ou seja, há também uma adequação do(s) espaço(s) ao contexto das necessidades locais e muitas particularidades nas formas de interação social. Com a leitura de Certeau, entende-se que não pode ser desconsiderada a capacidade dos indivíduos se apropriarem dos espaços a partir de determinada manipulação da ordem espacial. São as subversões, as táticas e que alteram o sentido da ordem, da estratégia. Assim, mesmo a pasteurização ou homogeneização dos espaços com uma produção material do tipo estandardizada não limitaria necessariamente a possiblidade de diferentes experiências e interações sociais. É o caso, por exemplo, de não-lugares que pertencem ao cotidiano de milhões de pessoas e que podem estabelecer determinados tipos de laços afetivos.

As reflexões e considerações deste artigo permitem somente um apontamento comum. Todas as abordagens conceituais sobre lugares e nãolugares, mais do que dividirem-se parecem ter a necessidade de somar-se para permitir a compreensão dos conceitos e dos papéis destas categorias na concretização da existência do homem. É o desafio de avançar frente à complexidade dos conceitos valendo-se de análises multidisciplinares para apreender a complexidade dos fenômenos globais em paralelo a rápida transformação da sociedade e de seus espaços de vivência. Neste aspecto, frisou-se também o cotidiano como categoria apontada por diferentes autores para entender analiticamente o lugar, ou mesmo não-lugar, e suas subjetividades relacionadas aos valores de pertencimento, afetividade, apropriação, vivência, resistência, transgressão. Pois se pode apontar uma hipótese de que a globalização em si não é capaz de anular a significância do lugar, mas antes determina que se reconstruam os sentidos de pertencimento. Lembrando Certeau, ao dizer que convém lembramos sempre que as pessoas não são idiotas, podemos supor que é no lugar que há um efetivo potencial de diferenciação em nossa época.

\section{Referências}

AUGÉ, Marc. Não-lugares: Introdução a uma antropologia da supermodernidade. Campinas, SP: Papirus, 1994.

BARTOLY, Flávio. Debates e perspectivas do lugar na geografia. GEOgraphia, Vol.13, nº 26, 2011.

BORDIEU, Pierre. A miséria do mundo. Petrópolis Rio de Janeiro: Editora Vozes Ltda., 1998, 752 p.

CARLOS, Ana Fani Alessandri."O lugar: mundialização e fragmentação. In: SANTOS, Milton et. al. (Org.) O novo mapa do mundo: fim de século e globalização. São Paulo: Hucitec, 1997.

CASTELO, Lineu. A percepção de lugar: repensando o conceito de lugar em arquitetura-urbanismo. Porto Alegre: PROPAR-UFRGS, 2007, 328 p.

CERTEAU, Michel de. A invenção do cotidiano: Artes de fazer. Petrópolis, RJ: Vozes, 1994.

COSTA, Fábio R. ROCHA, Márcio Mendes. Geografia: conceitos e paradigmas -apontamentos preliminares. Ver. GEOMAE Campo Mourão V.1 nำ, 2010, p. 25-56.

HARVEY, David. A condição pós-moderna. São Paulo: Edições Loyola, 2003.

SANTOS, Milton. A natureza do espaço: técnica e tempo, razão e emoção. São Paulo, Editora da Universidade de São Paulo, 2002.

SANTOS, Milton. Cadernos IPPUR/UFRJ/Instituto de Pesquisa e Planejamento Urbano e Regional da Universidade Federal do Rio de Janeiro - ano 1, n.1 (jan./abr. 1986) 0 Rio de Janeiro: UFRJ/IPPUR, 1986

SOUZA FILHO, Alípio. Michel de Certeau: fundamentos de uma sociologia do cotidiano. Sociabilidades. São Paulo/SP. V.2, p.129-134, 2002. 